http://www.jfas.info

\title{
AN INVESTIGATION ON DETONATOR TRIGGERING EFFECT SUBJECTED TO RADIO FREQUENCY ENERGY EXPOSURE
}

\author{
A. B. Z. Zuraida ${ }^{1,2, *}$, S. D. S. Fairuz ${ }^{1}$, M. S. Risby ${ }^{1}$, A. Amirah $^{2}$ and A. R. M. Raziff ${ }^{2}$ \\ ${ }^{1}$ Department of Electrical and Electronic Engineering, Faculty of Engineering, Universiti \\ Pertahanan Nasional Malaysia, Sungai Besi Camp, 57000 Kuala Lumpur, Malaysia \\ ${ }^{2}$ Universiti Kuala Lumpur BMI, 53100 Gombak, Selangor, Malaysia
}

Published online: 10 September 2017

\begin{abstract}
Nowadays, explosion phenomena are one of the exciting research especially in military field. In this paper, the study focus on investigation of the detonator triggering effect when subjected to radio frequency energy exposure from wireless local area network (WLAN). Electric detonator characteristics was used to design the test configuration to check the existence of current fluctuation in the wires during Wi-Fi exposure. The main interest is to observe for such cases, any premature fluctuation in the current flow connected to the detonator will be instigated prematurely upon setting up any wireless transmission during blast testing. Therefore, parameters such as cable specification, distance and acceptable current fluctuation is being further analyses. Preliminary test has found that there is no prematurely effect and the testing can be further implemented using real life detonator without the influence of blast materials such as TNT or PETN.
\end{abstract}

Keywords: blast; premature detonation; explosive; radio frequency energy.

Author Correspondence, e-mail: zurinzuraida@unikl.edu.my

doi: http://dx.doi.org/10.4314/jfas.v9i3s.3 


\section{INTRODUCTION}

Explosion phenomena one of the important and interesting research field to study especially for safety impact and expectation to environment. The explosion products initially expand at very high velocities to reach equilibrium with the surrounding air, causing a shock wave. A shock wave consists of highly compressed air, traveling radially outward from the source at supersonic velocities [1]. Shock waves or explosion normally is defined as a large scale, rapid and produced by the sudden release of energy from sources such as a chemical detonation, a nuclear explosion or the breach of a pressurized vessel. These waves are characterized by a supersonic shock front followed by an exponential-type decay of the physical properties of the gas [2]. When a shock wave is created by high explosive such as TNT (which has a detonation velocity of $6,900 \mathrm{~m} / \mathrm{s}$ ), it will always travel at high, supersonic velocity from its point of origin [3]. Dramatically, the highly explosion will affect the environmental such as the structure of the building nearby and the communication system. In the same time, the study will focus in the producing interference of radio frequency to wireless transmission system.

Wireless transmission system refers to the use of radio frequency (RF) that is one of the electromagnetic wave frequencies from around $3 \mathrm{KHz}$ to $300 \mathrm{GHz}$, which include those frequencies used for communications or radar signals. Normally, RF refers to electrical oscillations rather than mechanical. Although radio frequency is a rate of oscillation, it is also to describe the use of wireless communication as opposed to communication via electric wires. In this study, the wireless transmission system is more focus in Wi-Fi system. From previous study [4], Wi-Fi transmission can go further up to $100 \mathrm{~m}-1 \mathrm{~km}$ of distance coverage and it depends on the capacity of frequency band (eg: $2.4 \mathrm{GHz}$ or $5 \mathrm{GHz})$.

Wireless technology has come a long way since the development of wireless signalling techniques in the late 1800 s. Nowadays, wireless technologies of many types are used in a variety of applications, ranging from small application to huge application like satellite communications. A particular wireless technology is chosen (e.g: Wi-Fi IEEE 802.11n at $2.4 \mathrm{GHz}$ and $5 \mathrm{GHz}$ ) for a given application because the performance characteristics of that technology best align with the application requirements. A wireless device performance is greatly characterized by the frequency bands it operates. The higher its frequency i.e. $5 \mathrm{GHz}$, 
there is less noise in its transmission and offers better resilience albeit at a shorter distance. However, at a lower frequency i.e. $2.4 \mathrm{GHz}$, the signal can go at a farther distance and offers better coverage than the $5 \mathrm{GHz}$. Both frequency has high data transmission rate and bandwidth $[5]$.

In [6] reported that the probability of premature triggering which leads to unexpected detonation of electric detonators due to RF energy is relatively small. However, they noted that there have been real cases in which detonators were prematurely triggered by RF transmission to the detonator wires. Follow up investigations showed that the incident would not have occurred if certain or stipulated safe distances from the RF sources had been maintained.

Blasting is normally the initial phase in any mining procedure and its outcome impact the productivity of procedure to changing degrees. Normally, a powerful detonation will be produced high impact of blasting or explosives. Detonation is the process of spread of a shock wave through an explosive. To make sure the shock wave propagation is in stable manner, a chemical reaction from blasting will furnishes energy [7-8]. Detonators are normally initiated from the devices that with high explosive. In order to have a secure and controlled explosion, a detonator is used. The detonator contains highly sensitive explosives that either can be detonated by mechanical force or electrical initiation. There are various grades of detonator which defines the strength of explosion intended [8]. In explosive industry nowadays, the device that may be used to start a detonation for explosive is called initiator. As far as detonator concern, this is the development of detonators based in Fig. 1 [9].

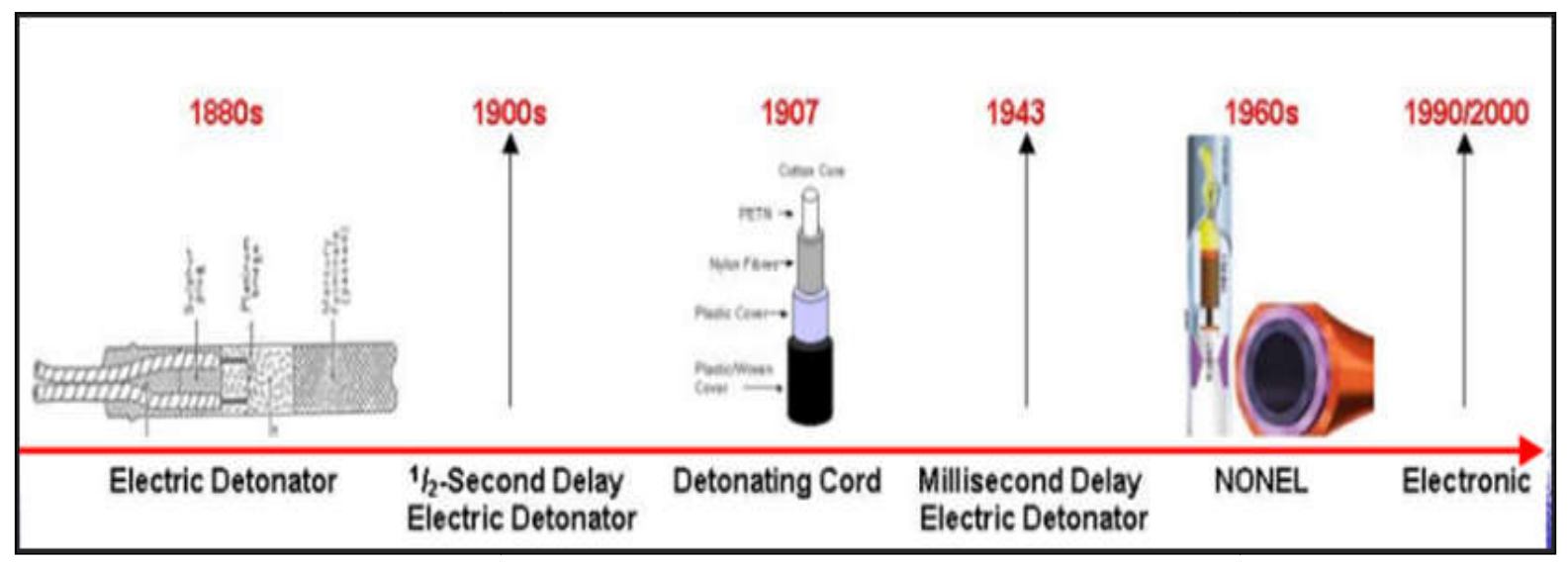

Fig.1. Development of detonators [9] 
Generally, detonators can be of two types: Electrical (electric system) and hitting (non-electric system). A hitting detonator responds to some type of mechanical force to activate an explosive. An electrical detonator responds to predefined electrical signal to activate an explosive. But there are various hazards associated with the electrical detonators like accidental initiation due to electrostatic discharge or radio frequency interference (if any), improper firing of the circuit or problem in delay or logic of the circuit. So, there was a need to develop a low energy, reliable and safe initiator in order to prevent disasters [6]. In this experiment, only the electrical system is considered because it is the premise of the ongoing experiment conducted for this project.

Electric detonators are broadly used to trigger the explosive especially in the case of landmine. Among all the types of blasting, the most effective is the electric type with the exceptions that it is to be used where there is no external presence of electrical disturbances. However, incidental sources powers can trigger the detonator which resulted in premature initiation of electric detonator due to Wi-Fi transmission energy. The previous conceptual design by [10] cited that there is no technically proven in the cases of detonators were prematurely initiated by electric detonators due RF energy in term of Wi-Fi communication.

The basic exploding bridge wire detonator firing circuit in Fig. 2 consists of a power supply to charge the firing capacitor $\mathrm{C}$ through the charging resistor $\mathrm{R}$, and a triggered spark gap switch to discharge the firing capacitor across the bridge wire via the transmission line (firing lead). To ensure a sufficiently rapid discharge for proper functioning of the detonator, it is very important that the total circuit inductance be kept low. In practice, this limits the firing wire length under ideal conditions to about $3 \mathrm{~m}$. In the Weapons System Division firing circuit a $1 \mathrm{uF}$ firing capacitor is charged to $3.0 \mathrm{kV}$ and the measured circuit inductance (for a $5 \mathrm{~m}$ firing cable) is about $2 \mathrm{uH}$ as reported in [11]. 


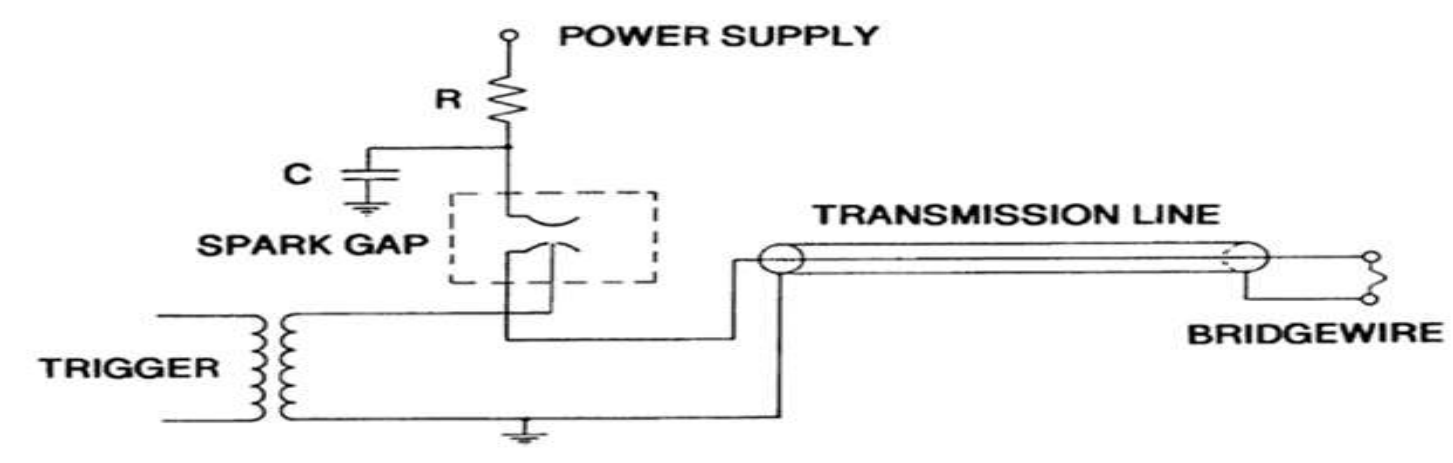

Fig.2. Basic circuitry of exploding bridge wire [11]

The specification of wire from [12] (technical data sheet) also must be consider to fulfil the requirement for detonator triggering especially used for blasting works together with explosives. Table 1 shows the specification of wires for detonator triggering.

Table 1. Specification of wire for detonator triggering (short delay detonators)

\begin{tabular}{cc}
\hline Specification & Description \\
\hline Tube Length & $54-67 \mathrm{~mm}$ \\
Tube material & Aluminium \\
Leg Wire Length & $4 \mathrm{~m}$ twin wire \\
Leg Wire Material & Copper \\
Leg Wire Diameter & $0.6 \pm 0.01 \mathrm{~mm}$ \\
Delay Time & $25 \mathrm{~ms}-500 \mathrm{~ms}$ \\
Resistance & $1.0-2.5 \Omega$ \\
Safety Current & $0.18 \mathrm{~A}, 5 \mathrm{minutes}$ \\
Single Initiate Current & $0.45 \mathrm{~A}$ \\
\hline
\end{tabular}

\section{EXPERIMENTAL}

In an ideal condition, a preliminary test is conducted in order to verify, if there is any incidental power source that can trigger and cause premature initiation to the detonators. The first experiment is to test and validate the functionality of wireless transmission system that will be used in this project prior to the preliminary testing. Fig. 3 and Fig. 4 show the wireless transmission and equipment set-up. The result was recorded under optimal condition in term 
of path loss, signal strength and Wi-Fi positioning based on the distance from the transmitter using continuous wave transmission Wi-Fi IEEE $802.11 \mathrm{~g}$ at $2.4 \mathrm{GHz}$ and $5 \mathrm{GHz}$.

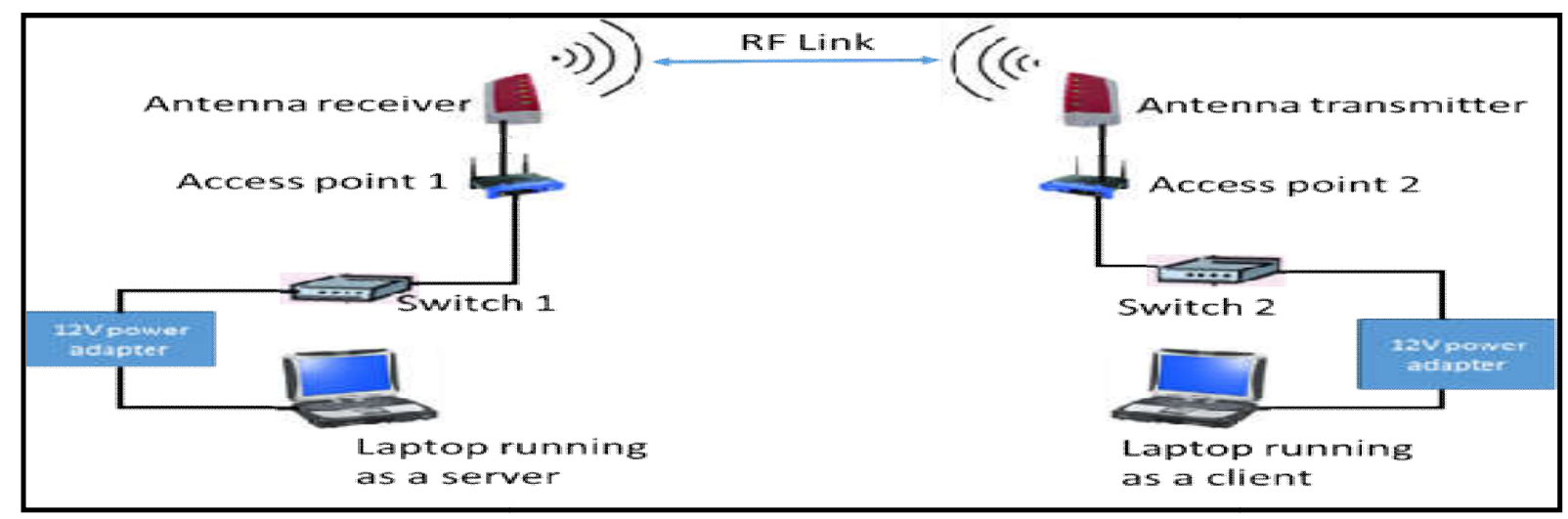

Fig.3. Wireless transmission set up

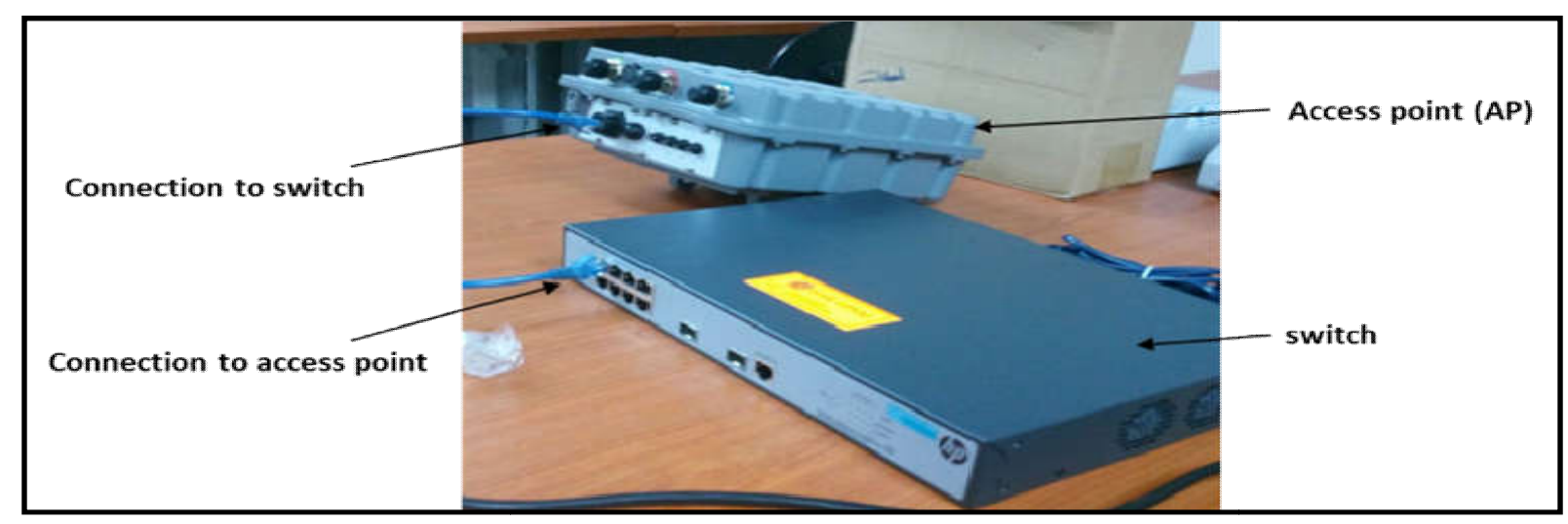

Fig.4. Equipment set up

The second experiment is to investigate and verify for any reaction or fluctuation in the wires of the circuit before explosion happened if the electric detonator wires is positioned in the area where strong RF signal is presence, especially in close proximity to the RF transmitter. The main reason wire is positioned at close proximity with Wi-Fi is to observe if there is any reaction or effect from the frequency generated by the Wi-Fi to the circuit diagram before pre-detonation. The basic procedure for conducting the test is via the close loop circuit. This circuit is sensitive to the electromagnetic wave. Fig. 5 illustrates the previous proposed blast experiment by [10], which is the conceptual design of wireless system in vehicle blast testing. Fig. 6 shows the preliminary set up to validate the previous problem statement. The distance between wireless system equipment, the wire connected to the circuit diagram and load is about 5 meters. This circuit (Fig. 7) consists of source, resistant and about 50 meters of wire laid and connected to the load in order to measure the current passing through the circuit. The 
expected result is to detect whether any premature fluctuation in the current flow connected to the detonator will be generated upon setting up of the wireless transmission during blast testing. During the testing, safety precaution should be considered to prevent destruction.

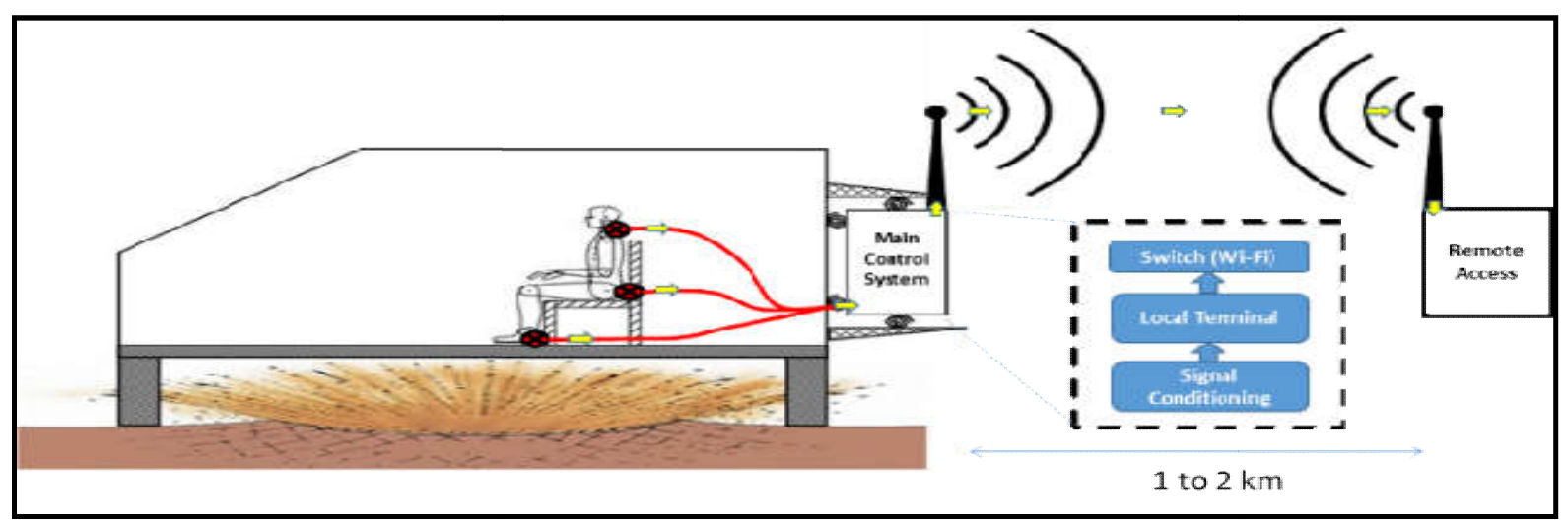

Fig.5. Previous proposed blast experiment [10]

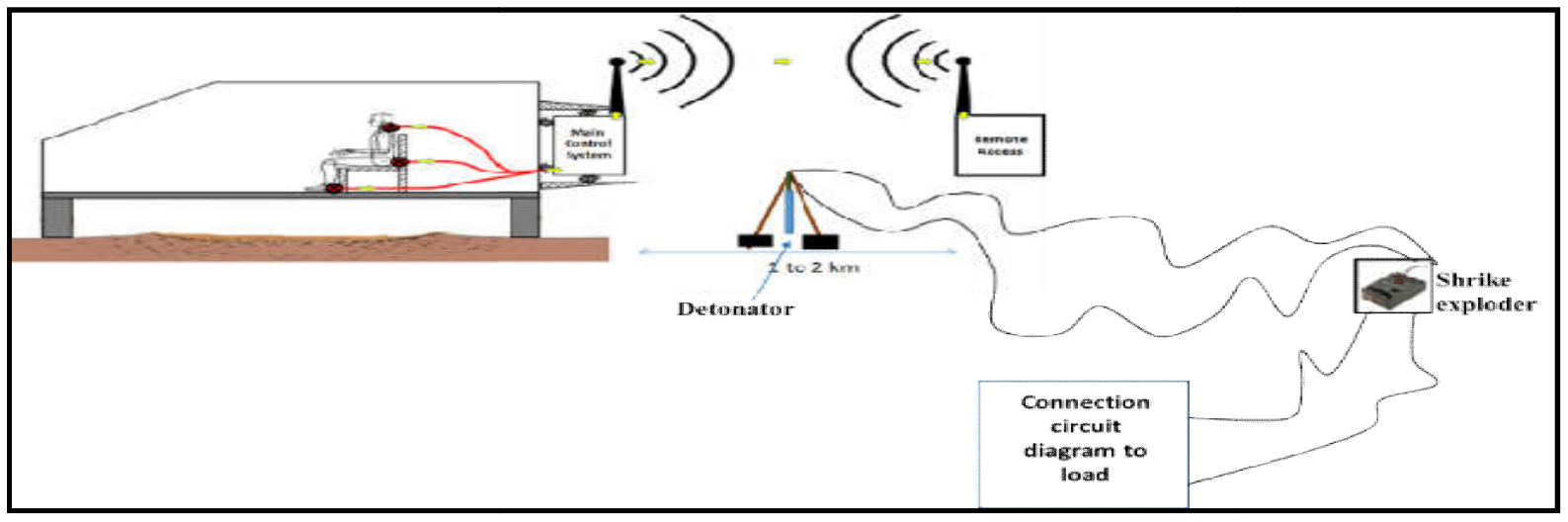

Fig.6. Experimental set up

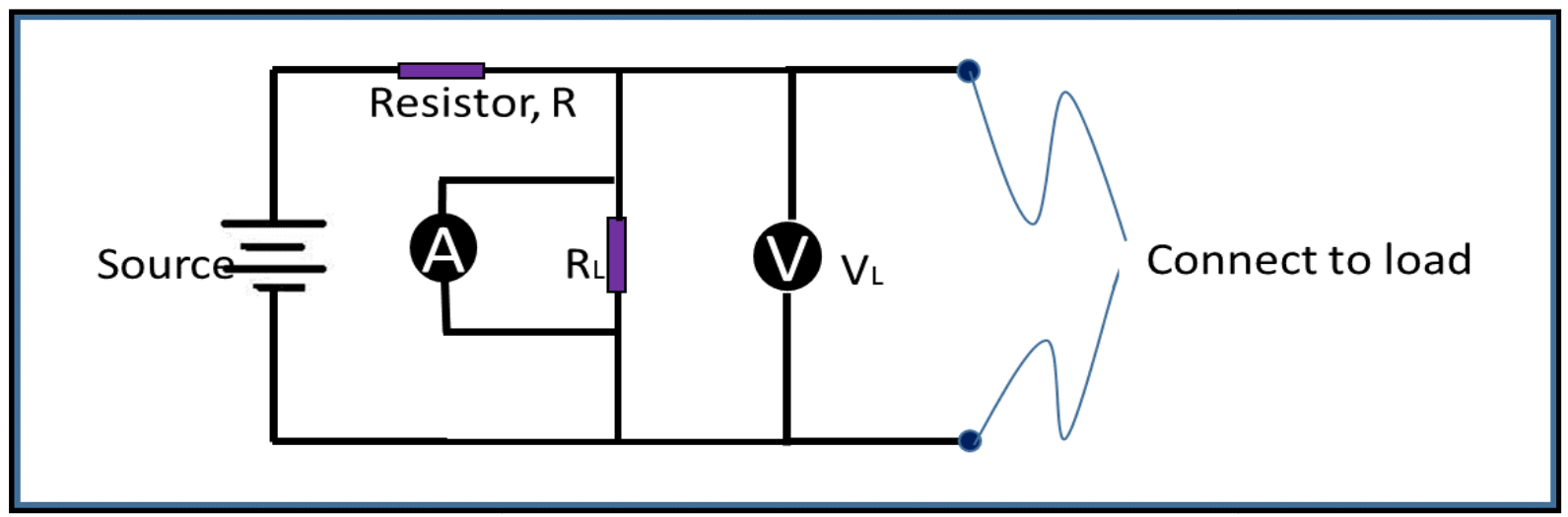

Fig.7. Circuit diagram

\section{RESULTS AND DISCUSSION}

The data tabulated below shows the performance result for a pilot test under optimal condition 
using Wi-Fi transmission band of $5 \mathrm{GHz}$ and $2.4 \mathrm{GH}$ as shown in Table 2 and Table 3 . The packet losses in the table are zero value $(0 \%)$, meaning the data transmitted and received are $100 \%$. There are no interferences in the transmission system or any triggering (reduced) values during preliminary testing which means that the signal strength is at highest level and stable condition. The graph of signal strength versus distance for both $5 \mathrm{GHz}$ and $2.4 \mathrm{GHz}$ (Fig. 8 and Fig. 9) shows slightly straight line which means that the transmission is stable and in good condition.

Table 4 shows the value of voltage $\left(\mathrm{V}_{\mathrm{L}}\right)$ and current $\left(\mathrm{R}_{\mathrm{L}}\right)$ are consistent in both with Wi-Fi and without Wi-Fi condition even though the value of resistance increased. It found that there is no fluctuating voltage and current in the wire or cable during the premature initiation test. Therefore, no electrical pulses generated during the setting up of the blasting process can self-trigger the detonators and also no premature fluctuation in the current flow connected to the detonator was generated upon setting up of the wireless transmission.

Table 2. Pilot test under optimal condition with $5 \mathrm{GHz}$

\begin{tabular}{cccc}
\hline Distance from Antenna, (m) & Signal Strength, dBm & Delay (ms) & Packet Loss (\%) \\
\hline 1 & -13 & 58 & 0 \\
2 & -11 & 42 & 0 \\
3 & -16 & 28 & 0 \\
4 & -12 & 41 & 0 \\
5 & -14 & 45 & 0 \\
6 & -11 & 37 & 0 \\
7 & -13 & 50 & 0 \\
8 & -12 & 50 & 0 \\
9 & -15 & 39 & 0 \\
10 & -14 & 37 & 0 \\
12 & -20 & 28 & 0 \\
14 & -17 & 43 & 0 \\
16 & -15 & 43 & 0 \\
18 & -12 & 77 & 0
\end{tabular}




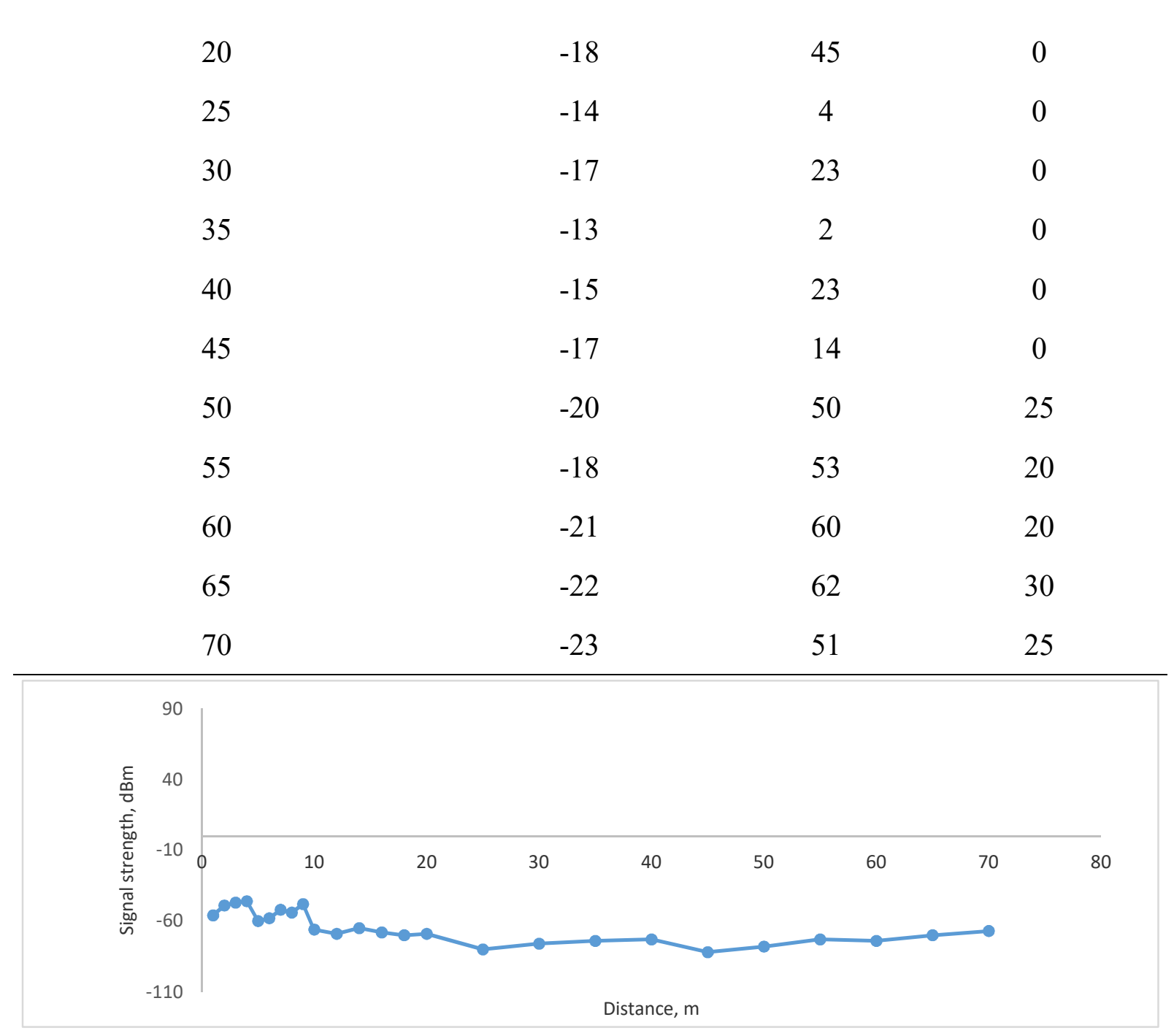

Fig.8. Signal strength versus distance of antenna performance for $5 \mathrm{GHz}$

Table 3. Pilot test under optimal condition with $2.4 \mathrm{GHz}$

\begin{tabular}{cccc}
\hline Distance from Antenna, (m) & Signal Strength, dBm & Delay (ms) & Packet Loss (\%) \\
\hline 1 & -13 & 58 & 0 \\
2 & -11 & 42 & 0 \\
3 & -16 & 28 & 0 \\
4 & -12 & 41 & 0 \\
5 & -14 & 45 & 0 \\
6 & -11 & 37 & 0 \\
7 & -13 & 50 & 0 \\
9 & -12 & 50 & 0
\end{tabular}




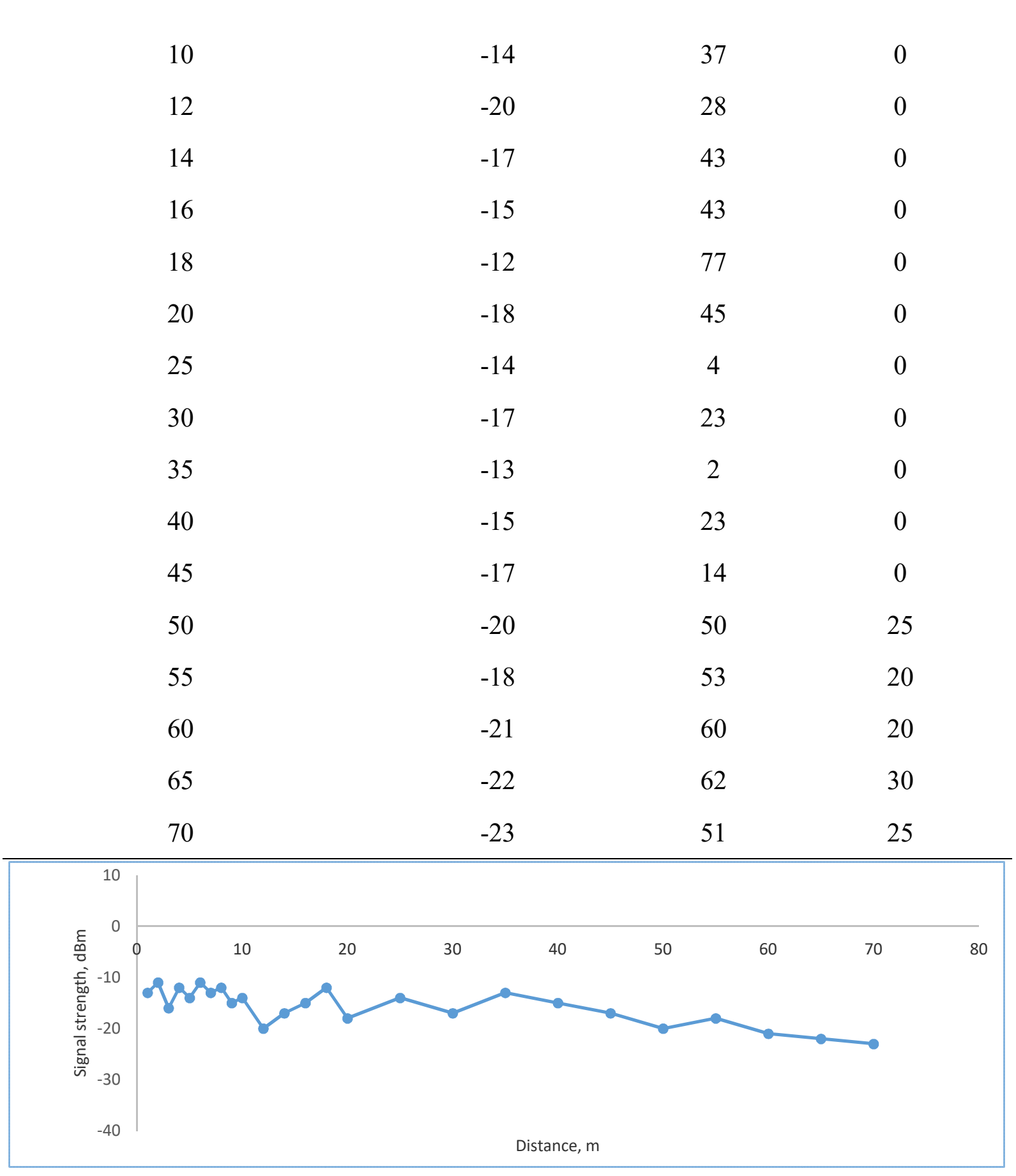

Fig.9. Signal strength versus distance of antenna performance for $2.4 \mathrm{GHz}$ 
Table 4. Preliminary test result for premature initiation

\begin{tabular}{cccc}
\hline \multicolumn{4}{c}{ With Wi-Fi } \\
R= 1k & $\mathbf{R}=\mathbf{1 0 k}$ & $\mathbf{R}=\mathbf{4 7 k}$ \\
\hline Voltage, (V) & 6.75 & 6.73 & 6.74 \\
Current, (mA) & 0.01 & 0.01 & 0.01 \\
& Without Wi-Fi & \\
Voltage, (V) & R $=1 \mathrm{k}$ & $\mathrm{R}=10 \mathrm{k}$ & $\mathrm{R}=47 \mathrm{k}$ \\
Current, (mA) & 0.75 & 6.73 & 6.74 \\
\hline
\end{tabular}

In future, a study will be done to investigate the triggering effect of the wireless transmission which involves high explosive blast and to show the correlation between the so-called standard proposed in the NATO manual [13] with an actual testing using real wireless transmission link for DAQ system.

\section{CONCLUSION}

In this paper, the preliminary test was set up under close loop circuit which is used to investigate certain parameters such as wire specification, distance and acceptable current fluctuation for wireless DAQ system under blast condition. In the preliminary tests conducted, it has been found that there is no premature current fluctuation generated that can self-trigger the electric detonator due to interferences from the RF transmission. In optimal condition for both $5 \mathrm{GHz}$ and $2.4 \mathrm{GHz}$, the RF [14] transmission system is in stable condition. The next step is to further test the same condition under real detonator set up albeit without explosive materials, but the detonator itself can explode into small shrapnel which can cause severe harm.

\section{ACKNOWLEDGEMENTS}

The authors wish to acknowledge the research grant provided by Long Term Research Grant Scheme (LRGS/B-U/2013/UPNM/DEFENCE\&SECURITY-P3) from the Malaysian Ministry of Education, which lead to the realization of this work. 


\section{REFERENCES}

[1] Terrorist P, Against A. Explosive blast. Buildings, 1995, 1-14

[2] Ngo T, Mendis P, Gupta A, Ramsay J. Blast loading and blast effects on structures-An overview. Electronic Journal of Structural Engineering, 2007, 7(S1):76-91

[3] Baker W. E. Explosions in air. Austin: University of Texas Press, 1973

[4] Bose E, Foh C H. A practical path loss model for indoor WiFi positioning enhancement. In 6th International Conference on Information, Communications and Signal Processing, 2009, pp. $1-5$

[5] Dickinson D P. So many wireless technologies ... Which is the right one for my application? Pennsylvania: Phoenix Contact, 2014

[6] Strong J. H., Turner J. H., Wortham M. W., Berry C. K. A guide to radio frequency hazards with electric detonators. North Carolina: NC Department of Labor, 2003

[7] Lai J, Fan H, Chen J, Qiu J, Wang K. Blasting vibration monitoring of undercrossing railway tunnel using wireless sensor network. International Journal of Distributed Sensor Networks, 2015, 2015: 1-7

[8] Manzor S H, Choudhary B S. Detonator: Evolution, classification and comparison. International Journal of Research in Aeronautical and Mechanical Engineering, 2014, 2(4):20-28

[9] Podoliak K. The evolution of the detonator. In New Leader's Conference, 2014, pp. 1-27

[10] Zurin Zuraida A B, Syed Fairuz S D, Risby M S. Conceptual design of wireless DAQ system for vehicle blast testing. Procedia Computer Science, 2016, 94:502-509

[11] Wolfson M G. A guide to explosive firing. Victoria: Defence Science and Technology Organisation (DSTO) Aeronautical and Maritime Research Laboratory, 1996

[12] Tenaga Kimia Sendirian Berhad (TKSB). Technical data sheet: Short delay detonators. Selangor: Tenaga Kimia Sendirian Berhad, 2013

[13] North Atlantic Treaty Organization (NATO)/Partnership for Peace (PfP). Procedures for evaluating the protection level of logistic and light armoured vehicles. Allied Engineering Publication, 2011, pp. 1-63

[14] Fauzi A, Rizman Z I. Design and fabrication of 12 GHZ microstrip directional coupler 
for RF/microwave application. Journal of Engineering Science and Technology, 2016, $11(3): 431-442$

\section{How to cite this article:}

Zuraida ABZ, Fairuz SDS, Risby MS, Amirah A, Raziff ARM. An investigation on detonator triggering effect subjected to radio frequency energy exposure. J. Fundam. Appl. Sci., 2017, 9(3S), $28-40$. 